\title{
Umweltprivatrecht in Deutschland und Polen unter europarechtlichem Einfluss
}

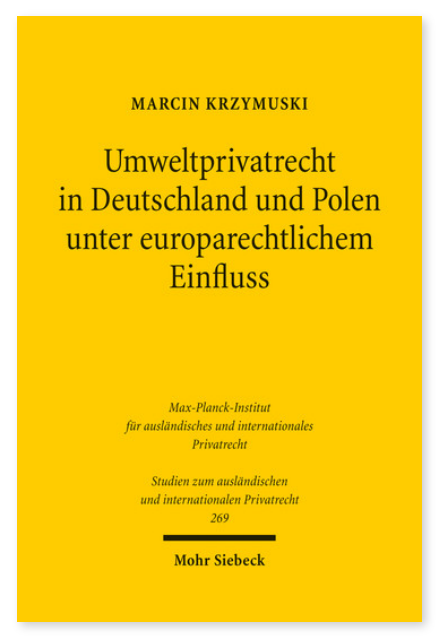

2012. XXVIII, 312 Seiten. StudIPR 269

ISBN 978-3-16-151857-7

DOI 10.1628/978-3-16-151857-7

eBook PDF 79,00€

ISBN 978-3-16-151705-1

fadengeheftete Broschur 79,00€
Grenzüberschreitende Umwelteinwirkungen berühren verschiedene Rechtssysteme und Rechtsgebiete, darunter auch das internationale und nationale Privatrecht. Für die privatrechtliche Aufarbeitung international wirkender Umweltschädigungen ist die Kenntnis von kollisionsrechtlichen Instrumenten und nationalen Umwelthaftungsansprüchen unverzichtbar. Die Arbeit von Marcin Krzymuski ist zunächst Wegweiser für die Feststellung des anwendbaren Rechts (internationales Delikts- und Sachenrecht). Dem schließt sich eine systematische Zusammenstellung von privatrechtlichen Ansprüchen des deutschen und polnischen Rechts an. Sie verschafft einen Überblick über die Gemeinsamkeiten und Unterschiede beider Rechtsordnungen hinsichtlich der Haftung für Schäden wegen beeinträchtigender Umwelteinwirkungen. Im Zusammenhang damit wird auch die Rolle von öffentlich-rechtlichen Genehmigungen sowie der Grenz- und Richtwerte besprochen.

Marcin Krzymuski Geboren 1974; Studium der Rechtswissenschaften an der Adam-Mickiewicz-Universität Pozna' n und der Europa-Universität Viadrina Frankfurt (Oder); seit 2005 wissenschaftlicher Mitarbeiter am Lehrstuhl für polnisches und europäisches Privatrecht sowie Rechtsvergleichung an der Europa-Universität Viadrina Frankfurt (Oder); seit 2006 Rechtsanwalt (radca prawny in Polen).
Jetzt bestellen:

https://mohrsiebeck.com/buch/umweltprivatrecht-in-deutschland-und-polen-unter-europarechtlichem-einfluss-

9783161518577?no_cache=1

order@mohrsiebeck.com

Telefon: $+49(0) 7071-923-17$

Telefax: $+49(0) 7071-51104$ 